\title{
Taking into account of natural and technological aspects of sustainable development of the forest complex when choosing a harvester manipulator
}

\author{
Sergey Karpachev", and Maksim Bykovskiy \\ Bauman Moscow State Technical University (Mytischi branch), 1st Institutskaya street, 141005 \\ Mytischi, Russia
}

\begin{abstract}
The article presents theoretical and experimental studies for choosing a manipulator for a harvester taking into account of natural and technological aspects of sustainable development of the forest complex. A mathematical model of the harvester operation is developed based on natural and technological factors, as well as the characteristics of the machine base and the harvester head. Experimental results allow us to determine the rational characteristics of the manipulator for Siberia region of Russia, in particular, the permissible overturn and load moments of the manipulator for the specified characteristics of the base machine and the selected harvesting head. The maximum outreach of the manipulator's boom in the range from 8000 to $11000 \mathrm{~mm}$ has little effect on the volume and number of harvested trees. The percentage of harvested wood volume almost does not depend on the maximum manipulator boom outreach and remains within at least $85 \%$.
\end{abstract}

\section{Introduction}

A significant effect on the basic operations of the technological cycle of the harvester, and hence on its productivity, provided by its technological equipment and in particular a manipulator, which accounts for $70-80 \%$ of the time the operating cycle of the harvester.

The harvester manipulator can be selected if the machine base is known and the harvester head is defined.

The paper considers the conditions of forests in Russian Siberia.

\section{Methods and mathematical model of manipulator operation}

The purpose of this work is to develop a method for selecting a manipulator based on the criteria of sustainable development of the forest complex and achieving maximum harvester productivity based on natural and technological factors, as well as the characteristics of the machine base and the harvester head.

\footnotetext{
* Corresponding author: karpachevs@mail.ru
} 
To achieve this goal, we used simulation methods with the mathematical models [1-2].

In this work, the technological process of the harvester was modeled taking into account the following factors [3-10]:

1. Natural:

- number of trees within the working zone;

- diameter of each tree at the cutting point;

- weight and volume of each tree.

2. Technological:

- cycles of processing time for each tree (the processing of the tree includes bucking);

- maximum $R_{\max }$ and minimum $R_{\min }$ boom outreach of the manipulator, which limit the possible area of the working zone.

When felling trees, the following restrictive conditions were checked for the harvester head and for the manipulator:

1. The diameter of the tree at the cutting point must be less than the maximum width of the harvester head. If this condition is not met, the tree remains in the working zone.

2. The weight of the tree creates a load moment less than the permissible load moment of the manipulator.

3. The weight of the tree creates an overturning moment less than the stabilizing moment of the harvester.

If condition 1 is met, but condition 2 or 3 is not met, the harvester will be forced to move off the route and be positioned at a minimum distance from the tree. If, when harvester approaching a tree at the minimum distance, the restrictive conditions for moments is not met, the tree remains in the cutting area.

When modeling stands, we took into account not only the average taxation indicators of forests, but also the law distribution of the number of trees within working zone and their volumes by diameter.

The diameter at the point where the tree was cut down was defined as a random continuous number. When generating tree diameters in the model we used a beta distribution with a range of diameters variations, which were established experimentally.

The limiting conditions associated with the weight of the processed tree are the combination of the load moment and the overturning moment of the harvester [3-4].

The load moment checks of the manipulator (Fig. 1) (the restriction associated with the breakage of the manipulator due to overload) was performed for each $i$-th tree according to the condition:

$$
G_{\text {tree_i }} \leq \frac{1000 \cdot M_{\text {gross }} \cdot K}{R_{\text {man_i }}}-G_{\mathrm{HH}}
$$

where:

$M_{\text {gross }}$ - gross load moment of the manipulator, $\mathrm{kNm}$.

$K=0.725$ - conversion coefficient of gross load moment to net load moment;

$R_{\mathrm{man} \_}$i reach of the manipulator to the $i$-th tree, $\mathrm{m}$;

$G_{\mathrm{HH}}-$ weight of the harvester head, H.

The check of the harvester's stability against overturning for each tree was carried out according to the permissible overturning moment [3-4].

Permissible overturning moment according to the condition of longitudinal ( $\mathrm{Y}$-axis) stability:

$$
M_{\text {stab_y }} \geq M_{\text {over_yi }}
$$




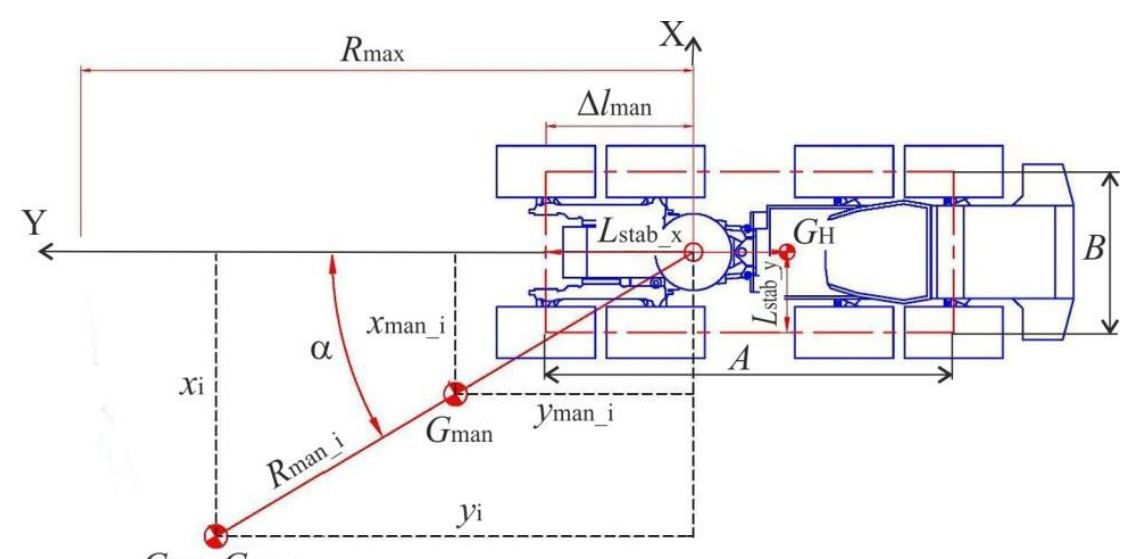

$G$ HH, Gtree_i

Fig. 1. Calculation scheme of forces acting on a harvester

Permissible overturning moment for lateral (X-axis) stability condition:

$$
M_{\text {stab_x }} \geq M_{\text {over_xi }},
$$

where:

Stabilizing moment

$$
\begin{aligned}
& \text { Y-axis: } \quad M_{\text {stab_y }}=\frac{G_{\mathrm{H}} L_{\text {stab_x }}}{1,4} \\
& \text { X-axis: } \quad M_{\text {stab_y }}=\frac{G_{\mathrm{H}} L_{\text {stab_y }}}{1,4}
\end{aligned}
$$

Load moment from the weight of the tree

$$
\begin{aligned}
& \text { Y-axis: } \quad M_{\text {tree } \_ \text {yi }}=G_{\text {tree_i }} \cdot\left(R_{\text {man } \_\mathrm{i}} \cdot \cos \alpha-\Delta l_{\text {man }}\right) \\
& \text { X-axis: } \quad M_{\text {tree_xi }}=G_{\text {tree_ } \mathrm{i}} \cdot\left(R_{\text {man } \_\mathrm{i}} \cdot \sin \alpha-L_{\text {stab } \_\mathrm{y}}\right)
\end{aligned}
$$

The moment from the weight of the manipulator

$$
\begin{aligned}
& \text { Y-axis: } M_{\text {man_yi }}=G_{\text {man }} \cdot\left(0.42 \cdot R_{\text {man } \_\mathrm{i}} \cdot \cos \alpha-\Delta l_{\text {man }}\right) \\
& \text { X-axis: } M_{\text {man_xi }}=G_{\text {man }} \cdot\left(0.42 \cdot R_{\text {man } \_\mathrm{i}} \cdot \sin \alpha-L_{\text {stab } \_y}\right)
\end{aligned}
$$

The moment from the weight of the harvester head

$$
\begin{array}{ll}
\text { Y-axis: } & M_{\mathrm{HH} \_\mathrm{yi}}=G_{\mathrm{HH}} \cdot\left(R_{\mathrm{man} \_\mathrm{i}} \cdot \cos \alpha-\Delta l_{\mathrm{man}}\right) \\
\text { X-axis: } & M_{\mathrm{HH} \_\mathrm{xi}}=G_{\mathrm{HH}} \cdot\left(R_{\mathrm{man} \_\mathrm{i}} \cdot \sin \alpha-L_{\mathrm{stab} \_\mathrm{y}}\right)
\end{array}
$$

Total overturning moment

$$
\text { Y-axis: } \quad M_{\text {over_yi }}=M_{\text {tree_yi }}+M_{\text {man_yi }}+M_{\text {HH_yi }}
$$




$$
\text { X-axis: } \quad M_{\text {over__i }}=M_{\text {tree__i }}+M_{\text {man__i }}+M_{\text {HH__i }}
$$

$\alpha$ - the angle of rotation of the manipulator.

In case of non-fulfillment of conditions (1) or (2), or (3), in the model, the boom outreach of the manipulator was reduced to $4 \mathrm{~m}$. For this, in model the corresponding harvester maneuver was simulated. If conditions (1) or (2), or (3) were not met at the manipulator minimum outreach, the tree was considered not felled.

The productivity of the harvester per hour in the model was determined as the volume of all trees which were processed into assortments:

$$
\sum_{\mathrm{i}=1}^{\mathrm{N}} \sum_{\mathrm{j}=1}^{\mathrm{n}} T_{\mathrm{ij}}=3600 \Rightarrow \text { Productivity_per_hour }=\sum_{\mathrm{i}=1}^{\mathrm{N}} \sum_{\mathrm{j}=1}^{\mathrm{n}} \sum_{\mathrm{k}=1}^{\mathrm{n}_{\mathrm{a}}} V_{\mathrm{ijk}},
$$

where:

$T_{\mathrm{ij}}$ - time of the i-th tree processing cycle at the j-th stop point, s;

$V_{\mathrm{ijk}}$ - volume of the k-th assortment after the $\mathrm{i}$-th tree processing cycle at the $\mathrm{j}$-th stop point, $\mathrm{m}^{3}$;

$\mathrm{N}$ - number of stop points;

$\mathrm{n}$ - number of trees in the $\mathrm{j}$-th stop point that can be cut down and processed with the harvester head and manipulator;

$n_{a}$ - number of assortments on the $j$-th stop point when processing the $\mathrm{i}$-th tree.

The felling and bucking time of each tree is the cycle time of the harvester and is a random variable. The distribution of the cycle time was taken exponentially distributed.

\section{Results and Discussion}

This paper presents the results of a study of the effect on the output productivity of a harvester with a $750 \mathrm{~mm}$ harvester head and a line of manipulators with maximum boom outreach from 8000 to $11000 \mathrm{~mm}$.

A harvester with the following characteristics was chosen as the machine base (Fig. 1):

$A=5580 \mathrm{~mm}$ - length of the edge of overturning moment;

$B=2196 \mathrm{~mm}$ - width of the edge of overturning moment;

$L_{\text {stab_x }}=1098 \mathrm{~mm}-$ distance from the center of gravity of the harvester to the overturning lateral axis (X-axis);

$L_{\text {stab_y }}=3380 \mathrm{~mm}$ - distance from the center of gravity of the harvester to the overturning longitudinal axis ( $\mathrm{Y}$-axis);

$\Delta l_{\operatorname{man}}=2080 \mathrm{~mm}$ - distance from the axis of rotation (attachment of the manipulator) to the overturning lateral axis (X-axis);

$G_{\mathrm{H}}=159475.4 \mathrm{~N}-$ weight of the harvester;

$G_{\mathrm{HH}}=13524 \mathrm{~N}$ - weight of the harvester head with rotator;

$G_{\text {man }}$ - weight of the manipulator, which changes in calculations depending on its maximum boom outreach.

Some research results are presented in the form of dependencies shown in the graphs in Fig. 4-5.

The graph in Fig. 2 shows that the total volume of cut trees increases with the increasing maximum manipulator boom outreach. This is to be expected, because the area of the working zone of the harvester is increased. It should be noted that this increase is insignificant and $11000 \mathrm{~mm}$ manipulator does not give a special advantage, compared to the $8000 \mathrm{~mm}$ manipulator. For example, the total volume of trees covered by the $8000 \mathrm{~mm}$ manipulator is $24.44 \mathrm{~m}^{3} / \mathrm{h}$, and the $11000 \mathrm{~mm}$ manipulator is $24.65 \mathrm{~m}^{3} / \mathrm{h}$. That is, the 
growth is only $1 \%$. According to this indicator, the impact of maximum boom outreach of the manipulator is insignificant.

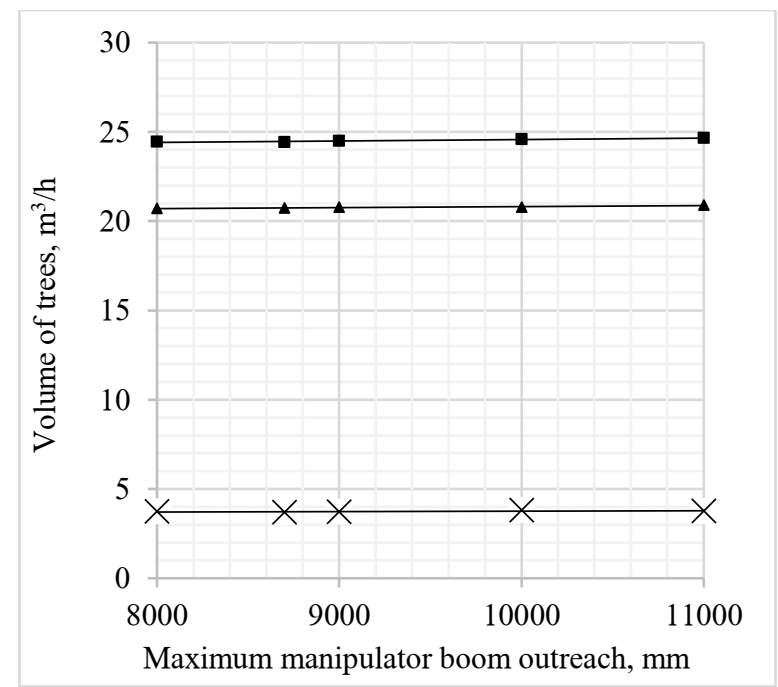

Fig. 2. Dependence of the volume of trees on the maximum manipulator boom outreach

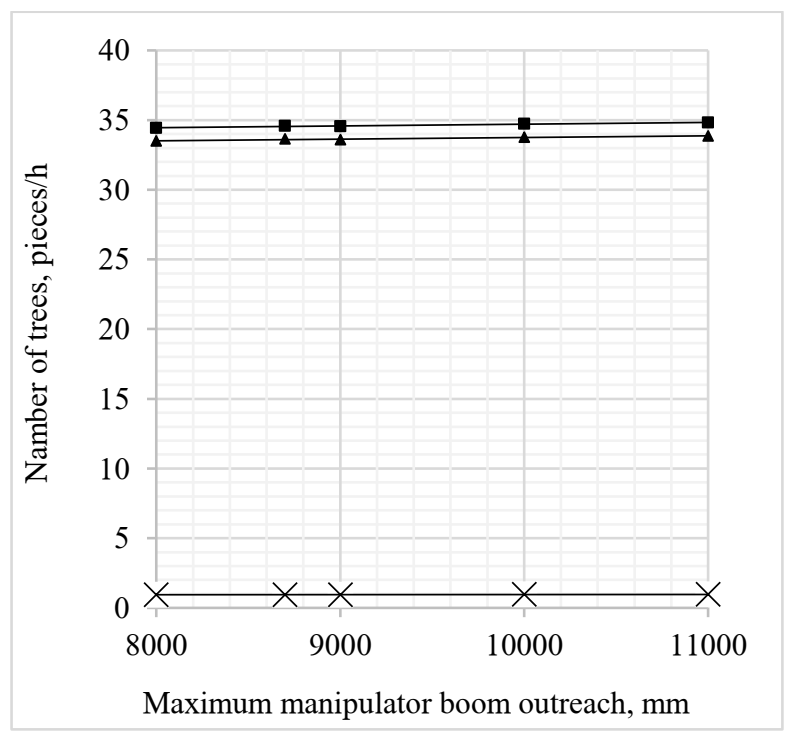

Fig. 3. Dependence of the number of the trees on the maximum manipulator boom outreach

The volume of harvested trees increases with the maximum boom outreach of the manipulator, and the volume of trees left in the cutting area almost does not change (Fig.4). For example, when the manipulator maximum outreach is $8000 \mathrm{~m}$, the volume of harvested trees is $20.71 \mathrm{~m}^{3} / \mathrm{h}$. The volume of trees left is $3.73 \mathrm{~m}^{3} / \mathrm{h}$. When the manipulator maximum outreach is $11000 \mathrm{~m}$, the corresponding volumes will be equal to 20.89 and $3,76 \mathrm{~m}^{3} / \mathrm{h}$. Thus, the growth in productivity with maximum manipulator boom outreach increase from 8000 to $11000 \mathrm{~mm}$ was less than $0.9 \%$. According to this indicator, the impact of the maximum manipulator boom outreach is insignificant.

The number of harvested trees (Fig.3) is also almost unchanged. 
For example, the number of harvested trees by the $8000 \mathrm{~mm}$ manipulator is 33.49 units/h., and the $11000 \mathrm{~mm}$ manipulator is $33.86 \mathrm{units} / \mathrm{h}$. That is, the growth is no more than $1 \%$.

The number of trees left in the cutting area remains less than 1 pieces/h. The fluctuation does not exceed 1\%. According to this indicator, the impact of the manipulator's maximum boom outreach is insignificant.

\section{Conclusions}

Simulation experiments for the selected harvester with a $750 \mathrm{~mm}$ harvester head and manipulators with maximum boom outreach from 8000 to $11000 \mathrm{~mm}$ allowed us to draw the following conclusions (for Russian Siberia conditions):

1. With increasing the maximum manipulator boom outreach the volume of harvested trees is increasing, that is, the productivity of the harvester. However, this growth is insignificant and does not exceed $0.9 \%$.

2. With increasing the maximum manipulator boom outreach the number of harvested trees also is increasing. However, this growth is insignificant and does not exceed $1 \%$.

3 . The percentage of harvested trees volume almost does not depend on the maximum manipulator boom outreach and remains within at least $85 \%$.

4. The percentage of harvested trees practically does not depend on the maximum manipulator boom outreach and remains more than $97 \%$.

Work has been performed in Bauman Moscow State Technical University with a financial support of the Russian Ministry of Education under Agreement No. 075-11-2019-030 dd 22 November 2019.

\section{References}

1. S.P. Karpachev, V.I. Zaprudnov, M.A. Bykovskiy, E.N. Scherbakov, Croat. j. for. eng., 38, 33 (2017)

2. S.P. Karpachev, V.I. Zaprudnov, M.A. Bykovskiy, I.P. Karpacheva, Croat. j. for. eng., 41, 95 (2020)

3. A.V. Laptev, Lesnoy vestnik/Forestry Bulletin, 93, 85 (2013)

4. A.V. Laptev, A.V. Matrosov, Lesnoy vestnik/Forestry Bulletin, 22, 77 (2018)

5. A.P. Mokhirev, A.A. Keryushchenko, Forest Messenger /Forestry Bulletin, 21, 17 (2017)

6. L. Eliasson von Hofsten, H., Johannesson, T., Spinelli, R., T. Thierfelder, Croat. j. for. eng., 36, 11 (2015)

7. Y. Gerasimov, A. Seliverstrov, Croat. j. for. eng., 30, 111 (2010)

8. A. B. Adebayo, H. Han, L. Johnson, Forest Products Journal, 57, 59 (2007)

9. J. Eronen, A. Asikainen, J. Uusitalo, L. Sikanen, Forest Products Journal, 50, 65 (2000)

10. A.P. Konovalov, A.A. Seliverstov, Forestry Expert, 1, 76 (2008) 